\title{
Outcome of HLA-matched related allogeneic hematopoietic stem cell transplantation for patients with acute leukemia in first complete remission treated in Eastern European centers. Better results in recent years
}

\author{
Sebastian Giebel • Myriam Labopin • Jerzy Holowiecki • Boris Labar • \\ Mieczyslaw Komarnicki • Vladimir Koza • Tamas Masszi • Martin Mistrik • \\ Andrzej Lange • Andrzej Hellmann - Antonin Vitek • Joze Pretnar • Jiri Mayer • \\ Piotr Rzepecki • Karel Indrak • Wieslaw Wiktor-Jedrzejczak • Jerzy Wojnar • \\ Malgorzata Krawczyk-Kulis • Slawomira Kyrcz-Krzemien • Vanderson Rocha
}

Received: 5 December 2008 / Accepted: 23 February 2009 /Published online: 20 March 2009

(C) Springer-Verlag 2009

\begin{abstract}
The goal of this study was to analyze results and to determine factors affecting outcome of HLA-matched hematopoetic stem cells transplantation (MRD-HSCT) for patients with acute leukemia transplanted in first complete remission in Eastern European countries. Six hundred forty HSCT were performed between 1990 and 2006 for adults with acute myeloid $(n=459)$ and lymphoblastic $(n=181)$ leukemia. Two-year leukemia-free survival (LFS), nonrelapse mortality (NRM), and relapse incidence were $58 \pm 2 \%, 19 \pm 2 \%$, and $23 \pm 2 \%$, respectively. The cumulative incidence of NRM
\end{abstract}

On behalf of the Acute Leukemia Working Party of the European Group for Blood and Marrow Transplantation

\footnotetext{
S. Giebel $(\bowtie) \cdot J$. Holowiecki

Department of Clinical Oncology, Comprehensive Cancer Center,

Maria Sklodowska-Curie Memorial Institute Branch Gliwice,

Wybrzeze Armii Krajowej 15,

44-101 Gliwice, Poland

e-mail: sgiebel@poczta.onet.pl

M. Labopin

European Group for Blood and Marrow Transplantation,

Acute Leukemia Working Party, Hopital Saint-Antoine,

Assistance Publique des Hôpitaux de Paris and Université de Paris 6,

Pierre et Marie Curie,

Paris, France

B. Labar

Department of Hematology,

University Hospital Center Rebro,

Zagreb, Croatia
}

decreased from $22 \pm 2 \%$ for patients treated between 1990 and 2002 to $15 \pm 3 \%$ for transplantations performed between 2003 and $2006(p=0.02)$, despite increasing recipient age. In a multivariate analysis, time of HSCT affected both NRM and LFS. Among other prognostic factors, the use of TBI decreased relapse incidence and increased the LFS rate. We conclude that results of MRD-HSCT for acute leukemia in Eastern Europe improved over time as a consequence of decreased NRM. The use of TBI containing regimens appears advantagous.

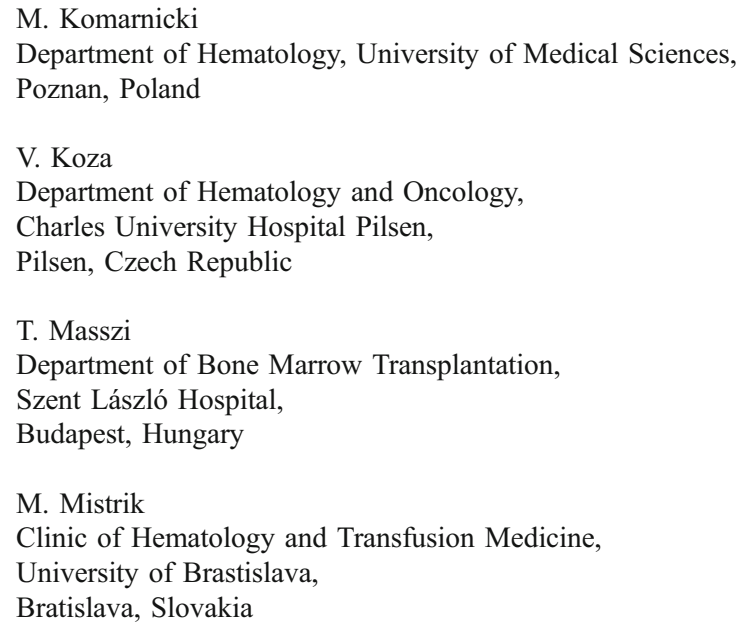


Key words Matched related donor HSCT - Acute leukemia Prognostic factors · Leukemia-free survival - Nonrelapse mortality

\section{Introduction}

Allogeneic hematopoietic stem cell transplantation from HLA-matched related donor (MRD-HSCT) is a wellrecognized option for the treatment of patients with acute leukemia in first complete remission (CR). The benefit of MRD-HSCT over conventional-dose chemotherapy with regard to relapse rate has been demonstrated in a number of analyses for both acute lymphoblastic leukemia (ALL) and acute myeloid leukemia (AML) [1-9]. The number of MRD-HSCT for acute leukemia in Europe has been continuously growing over the last decades [10]. However, as demonstrated by Gratwohl et al., transplantation rates varied strongly between countries, which in major part could be explained by different economical conditions defined by the gross national income (GNI) per capita [11]. In particular, the number of MRD-HSCT procedures performed per year per ten million inhabitants between year 1990 and 2003 in Eastern European countries, representing medium GNI per capita, was markedly lower compared to Western Europe [12]. This difference resulted initially from later introduction of MRD-HSCT in Eastern countries but has been maintained over years as a consequence of parallel increase in transplantation rates in both parts of the continent [12].

Among various factors influencing outcome of MRDHSCT, the role of center effect has been highlighted in recent years. Frassoni at al. demonstrated that NRM varies strongly among transplant centers and that this phenome-

A. Lange

Lower Silesian Center for Cellular Transplantation with National

Bone Marrow Donor Registry,

Wroclaw, Poland

A. Hellmann

Department of Hematology, Medical University of Gdansk,

Gdansk, Poland

A. Vitek

Institute of Hematology and Blood Transfusion,

Prague, Czech Republic

J. Pretnar

Department of Hematology,

University Medical Center Ljubljana,

Ljubljana, Slovenia

J. Mayer

Department of Internal Medicine, Hemato-Oncology,

University Hospital Brno,

Brno, Czech Republic non can partially be explained by the differences regarding team experience [13]. Provided that the MRD-HSCT has been widely introduced in Eastern Europe in the 1990s, i.e., approximately a decade later than in Western countries, it may be hypothesized that results in Eastern Europe are inferior and are characterized by higher rate of NRM. This issue is of particular importance in acute leukemia where the expected incidence of transplantation-related deaths should be taken into account for treatment decisions.

The goal of this study was to evaluate results of MRDHSCT for acute leukemia patients in Eastern Europe and to determine if the outcome changed over time. In addition, we searched for other prognostic factors related to donor, recipient, and procedure characteristics.

\section{Patients and methods}

Study design and data collection

This was a retrospective multicenter analysis. Data were provided by the registry of the Acute Leukemia Working Party of the European Group for Blood and Marrow Transplantation (EBMT). Centers participating in the EBMT are annually requested to report all consecutive stem cell transplantations and follow-up. The validation and quality control program includes verification of the computer print-out of the entered data, cross-checking with the national registries, and on-site visits of selected teams.

Criteria of selection

Inclusion criteria for the analysis were as follows: (1) Diagnosis of AML or ALL, (2) Age $\geq 16$ years, (3) MRD-

P. Rzepecki

Bone Marrow Transplantation Unit, Military Medical Academy, Warsaw, Poland

K. Indrak

Department of Hemato-Oncology, University Hospital Olomouc, Olomouc, Czech Republic

W. Wiktor-Jedrzejczak

Department of Hematology and Oncology,

Medical University of Warsaw,

Warsaw, Poland

J. Wojnar $\cdot$ M. Krawczyk-Kulis $\cdot$ S. Kyrcz-Krzemien

Department of Hematology and Bone Marrow Transplantation,

Silesian Medical University,

Katowice, Poland

V. Rocha

Department of Hematology, Hopital Saint-Louis,

Assistance Publique Hopitaux de Paris,

Paris, France 
HSCT performed between 1990 and 2006 in Eastern European countries, including those that entered the European Union after 2003 and those not being memberstates of the European Union, and (4) CR1 at transplantation.

Patients, donors, and procedure

Six hundred forty patients with the diagnosis of AML ( $n=$ $459)$ or ALL $(n=181)$ were included in the analysis. Transplantations were performed in 32 centers representing 10 countries (Poland, $n=178$; Czech Republic, $n=133$; Croatia, $n=60$; Hungary, $n=52$; Slovakia, $n=40$; Slovenia, $n=29$; Serbia, $n=17$; Estonia, $n=7$; Romania, $n=6$; Lithuania, $n=1)$. Median age of the recipients equaled 35 years (range, 16-69 years). Selection of donors was based either on serological or molecular methods at low resolution level.
All patients and donors were fully matched for HLA-A, HLA-B, and HLA-DR. The data on pre-transplant CMV serological status were available in 201 patient/donor pairs. CMV positivity was established in $63 \%$ of patients and $62 \%$ of donors. The conditioning regimen was myeloablative in $90 \%$ of cases and was based on either total body irradiation (TBI, mainly for ALL) or chemotherapy alone (predominantly for AML). Definition of reduced intensity conditioning regimen was considered lower dose of busulfan (less than $8 \mathrm{mg} / \mathrm{kg}$ total dose) or TBI (less than 6 Gy). The transplantations were performed using bone marrow (BMT) and peripheral blood (PBSCT) as a sources of stem cells in similar proportions. Ex vivo T-depletion was applied in seven cases (1\%). After transplantation patients were monitored CMV antigenemia or CMV-DNA. Detailed characteristics of patients, donors, and MRDHSCT procedure are listed in Table 1.
Table 1 Patients and donors: transplantation procedure
${ }^{\text {a }}$ Details on conditioning were available in $31 \%$ of patients among whom $54 \%$ received TBI-based regimen while $46 \%$, busulfan-based one

${ }^{\mathrm{b}}$ Details on conditioning were available in $54 \%$ of patients among whom $84 \%$ received fludarabine-based regimen while $16 \%$, TBI-based one

\begin{tabular}{|c|c|c|c|}
\hline & AML & ALL & Total \\
\hline$N$ & 459 & 181 & 640 \\
\hline Median patient age, range (years) & $39(16-68)$ & $25(16-58)$ & $35(16-69)$ \\
\hline \multicolumn{4}{|l|}{ Recipient gender } \\
\hline Male & $212(46 \%)$ & $112(92 \%)$ & $324(51 \%)$ \\
\hline Female & $244(54 \%)$ & $68(8 \%)$ & $312(49 \%)$ \\
\hline Unknown & 3 & 1 & 4 \\
\hline \multicolumn{4}{|l|}{ Donor gender } \\
\hline Male & $236(52 \%)$ & $102(57 \%)$ & $338(53 \%)$ \\
\hline Female & $216(48 \%)$ & $78(43 \%)$ & $294(47 \%)$ \\
\hline Unknown & 7 & 1 & 8 \\
\hline \multicolumn{4}{|l|}{ Donor/recipient gender } \\
\hline Female/male & $102(23 \%)$ & $44(24 \%)$ & $146(23 \%)$ \\
\hline Other combinations & $350(77 \%)$ & $136(76 \%)$ & $486(77 \%)$ \\
\hline Unknown & 7 & 1 & 8 \\
\hline $\begin{array}{l}\text { Median interval from diagnosis } \\
\text { to transplantation, range (days) }\end{array}$ & $187(23-933)$ & $196(55-668)$ & $190(23-933)$ \\
\hline Median year of transplantation, range & 2001 (1990-2006) & 2002 (1992-2006) & 2002 (1990-2006) \\
\hline \multicolumn{4}{|l|}{ Conditioning intensity } \\
\hline Myeloablative $^{\mathrm{a}}$ & $404(88 \%)$ & $174(96 \%)$ & $578(90 \%)$ \\
\hline Reduced $^{\mathrm{b}}$ & $55(12 \%)$ & $7(4 \%)$ & $62(10 \%)$ \\
\hline \multicolumn{4}{|l|}{ Type of conditioning } \\
\hline Chemotherapy-based & $381(85 \%)$ & $69(39 \%)$ & $450(66 \%)$ \\
\hline TBI-based & $68(15 \%)$ & $109(61 \%)$ & $177(34 \%)$ \\
\hline Unknown & 10 & 3 & 13 \\
\hline \multicolumn{4}{|l|}{ Source of stem cells } \\
\hline Bone marrow & $240(52 \%)$ & $106(59 \%)$ & $346(54 \%)$ \\
\hline Peripheral blood & $219(48 \%)$ & $75(41 \%)$ & $294(46 \%)$ \\
\hline \multicolumn{4}{|l|}{ Ex vivo T-depletion } \\
\hline No & $431(99 \%)$ & $173(98 \%)$ & $604(99 \%)$ \\
\hline Yes & $4(1 \%)$ & $3(2 \%)$ & $7(1 \%)$ \\
\hline
\end{tabular}




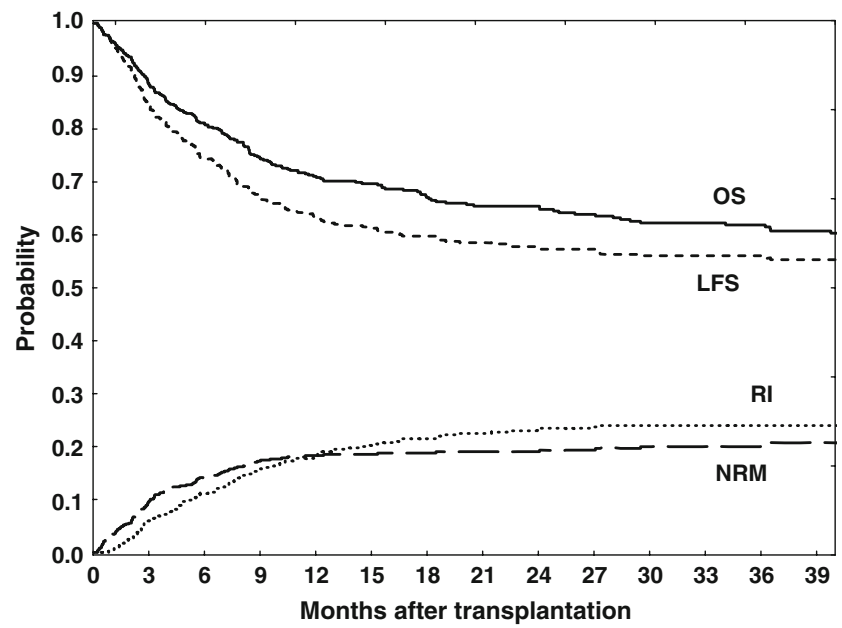

Fig. 1 Outcome of acute leukemia patients treated with MRD-HSCT in CR1 in Eastern Europe between 1990 and 2006

\section{Statistical analysis}

The following factors were analyzed for their prognostic value on each of the outcomes: year of MRD-HSCT, the diagnosis, interval from diagnosis to MRD-HSCT, recipient and donor characteristics (age, sex), and transplantation procedure (regimen intensity, use of TBI, stem cell source).

The probabilities of leukemia-free survival (LFS), relapse incidence (RI), and nonrelapse mortality (NRM) were the primary study endpoints. The LFS was defined as time interval from MRD-HSCT to either relapse or death in remission and was calculated using the Kaplan-Meier estimate. The RI and NRM were calculated using cumulative incidence curves in a competing risks setting, death in remission being treated as a competing event to relapse [14, 15]. Univariate analyses were done with the use of log-rank test for LFS while Grey's test was applied for RI and NRM. Continues variables were first categorized to divide the study group in five equal cohorts. Based on results of initial analysis, the final cutoff points were selected to be used in multivariate models. All potential prognostic factors with a $p$ value less than 0.20 in univariate analyses were included in the Cox proportional hazard model, together with year of transplantation, diagnosis, and recipient age.

Additional study endpoints included engraftment and acute graft-versus-host disease (GVHD), which were reported as proportions, the probability of the overall survival (OS) estimated using the Kaplan-Meier method, and chronic graft-vs.-host, analyzed as cumulative incidence, relapse and death in remission being considered as competing. For the comparisons of transplant characteristics in various periods, Mann-Whitney $U$ test and $\chi^{2}$ test were used, as appropriate. All $p$ values are two-sided with type 1 error rate fixed at 0.05 . Statistical analyses were performed with SPSS (Inc., Chicago) and S-Plus (MathSoft, Inc, Seattle) software packages.

\section{Results}

Engraftment and GVHD

Six hundred thirteen out of 632 evaluable patients $(97 \%)$ engrafted with the median time to neutrophil $>0.5 \times 10^{9} / \mathrm{L}$ recovery of 18 days (range, 5-60 days). The incidence of primary graft failure was $3 \%$ while secondary graft loss was diagnosed in $0.5 \%$ cases. One hundred fifty-seven out of 615 eligible patients $(26 \%)$ experienced grade II-IV acute GVHD, whereas the 2-year probability of chronic GVHD was $29 \pm 2 \%$.

\section{Nonrelapse mortality}

With the median follow-up of 21 months (range, 1157 months), the cumulative incidence of NRM was 19 (standard error (SE) $\pm 2 \%$; Fig. 1). For MRD-HSCT performed between years 1990 and 2002, the rates of NRM did not change significantly while the outcome for transplantations performed after 2002 improved in comparison with the preceding period $(22 \pm 2 \%$ vs. $15 \pm 3 \%, p=$ 0.02 ; Fig. 2). In a multivariate analysis, the only factors affecting the risk of NRM were the year of transplantation $(\mathrm{HR}=0.58$ for MRD-HSCT performed after year 2002) and the recipient age $\geq 40$ years ( $\mathrm{HR}=1.48$; Table 2 ).

\section{Relapse incidence}

The cumulative incidence of RI was $23 \pm 2 \%$ for all patients (Fig. 1), $22 \pm 3 \%$ for AML, and $25 \pm 3 \%$ for ALL. No changes of RI rates were observed over time. In both

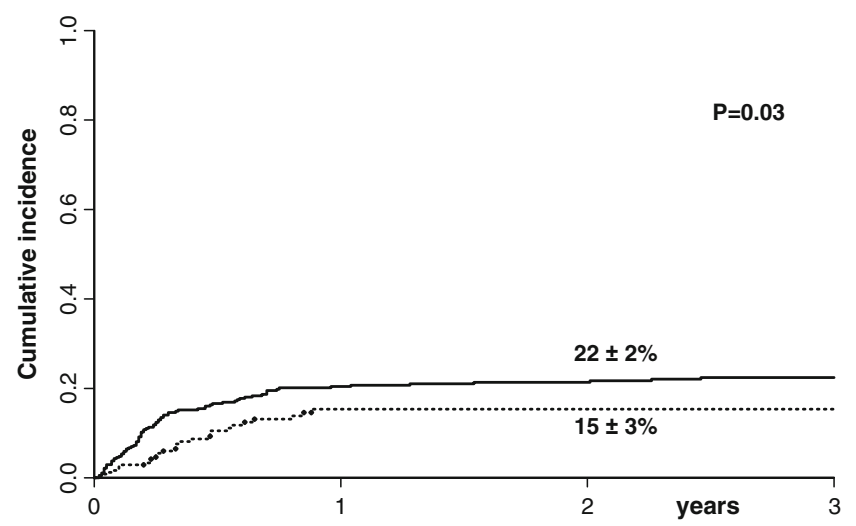

Fig. 2 Cumulative incidence of Non Relapse Mortality (NRM) in patients receiving MRD-HSCT between 1990 and 2002 (solid line) or in 2003-2006 (dotted line) 
univariate and multivariate analysis the use of peripheral blood resulted in increased risk of RI $(\mathrm{HR}=1.63)$ whereas female donor gender $(\mathrm{HR}=0.63)$, interval from diagnosis to MRD-HSCT $\geq 9$ months $(\mathrm{HR}=0.44)$, and TBI-based conditioning $(\mathrm{HR}=0.52)$ were associated with reduced incidence of relapse (Table 2).
Survival

The 2-year probabilities of OS and LFS for the whole group equaled $65 \pm 2 \%$ and $58 \pm 2 \%$, respectively (Fig. 1). The LFS rates were $59 \pm 3 \%$ for AML patients, and $55 \pm 4 \%$ for ALL.

Table 2 Factors affecting outcome after MRD-HSCT for acute leukemia in first complete remission

\begin{tabular}{|c|c|c|c|c|c|c|c|c|c|c|c|c|c|}
\hline \multicolumn{8}{|l|}{ Univariate analysis } & \multicolumn{6}{|c|}{ Multivariate analysis } \\
\hline & \multirow[t]{2}{*}{$N$} & \multicolumn{2}{|c|}{$\begin{array}{l}\text { Leukemia- } \\
\text { free survival }\end{array}$} & \multirow{2}{*}{$\begin{array}{l}\begin{array}{l}\text { Relapse } \\
\text { incidence }\end{array} \\
\text { 2-year CI }\end{array}$} & \multirow[b]{2}{*}{$\begin{array}{l}P \\
\text { value }\end{array}$} & \multirow{2}{*}{$\begin{array}{l}\begin{array}{l}\text { Nonrelapse } \\
\text { mortality }\end{array} \\
\text { 2-year } \\
\text { CI }\end{array}$} & \multirow[b]{2}{*}{$\begin{array}{l}P \\
\text { value }\end{array}$} & \multicolumn{2}{|c|}{$\begin{array}{l}\text { Leukemia-free } \\
\text { survival }\end{array}$} & \multicolumn{2}{|c|}{ Relapse incidence } & \multicolumn{2}{|c|}{$\begin{array}{l}\text { Nonrelapse } \\
\text { mortality }\end{array}$} \\
\hline & & $\begin{array}{l}\text { 2-year } \\
\text { KM }\end{array}$ & $\begin{array}{l}P \\
\text { value }\end{array}$ & & & & & $\begin{array}{l}\mathrm{HR} \\
(95 \% \mathrm{CI})\end{array}$ & $\begin{array}{l}P \\
\text { value }\end{array}$ & $\begin{array}{l}\mathrm{HR} \\
(95 \% \mathrm{CI})\end{array}$ & $\begin{array}{l}P \\
\text { value }\end{array}$ & $\begin{array}{l}\mathrm{HR} \\
(95 \% \mathrm{CI})\end{array}$ & $\begin{array}{l}P \\
\text { value }\end{array}$ \\
\hline Patient age & & & .015 & & .15 & & .09 & & .03 & & NS & & .045 \\
\hline$<40$ years & 393 & $61 \pm 3$ & & $21 \pm 2$ & & $17 \pm 2$ & & 1.0 & & - & & 1.0 & \\
\hline$\geq 40$ years & 247 & $53 \pm 4$ & & $25 \pm 3$ & & $22 \pm 3$ & & $\begin{array}{l}1.33 \\
(0.97- \\
1.03)\end{array}$ & & - & & $\begin{array}{l}1.48 \\
(1.01- \\
2.16)\end{array}$ & \\
\hline Diagnosis & & & .45 & & .73 & & .73 & & .02 & & NS & & NS \\
\hline AML & 459 & $59 \pm 3$ & & $22 \pm 3$ & & $18 \pm 2$ & & 1.0 & & - & & - & \\
\hline ALL & 181 & $55 \pm 4$ & & $25 \pm 3$ & & $20 \pm 3$ & & $\begin{array}{l}1.43 \\
(1.05- \\
1.96)\end{array}$ & & - & & - & \\
\hline Donor gender & & & .33 & & .016 & & .23 & & NS & & .01 & & NS \\
\hline Male & 338 & $54 \pm 3$ & & $28 \pm 3$ & & $18 \pm 2$ & & - & & 1.0 & & - & \\
\hline Female & 294 & $62 \pm 3$ & & $18 \pm 3$ & & $20 \pm 2$ & & - & & $\begin{array}{l}0.63 \\
(0.43- \\
0.9)\end{array}$ & & - & \\
\hline $\begin{array}{l}\text { Interval diagnosis- } \\
\text { transplantation }\end{array}$ & & & .03 & & .0005 & & .48 & & .04 & & .003 & & NS \\
\hline$<9$ months & 501 & $56 \pm 3$ & & $26 \pm 2$ & & $19 \pm 2$ & & 1.0 & & 1.0 & & - & \\
\hline$\geq 9$ months & 139 & $66 \pm 4$ & & $13 \pm 2$ & & $21 \pm 3$ & & $\begin{array}{l}0.69 \\
(0.49- \\
0.97)\end{array}$ & & $\begin{array}{l}0.44 \\
(0.26- \\
0.75)\end{array}$ & & - & \\
\hline Conditioning intensity & & & .02 & & .005 & & .95 & & & & & & \\
\hline Myeloablative & 578 & $59 \pm 2$ & & $22 \pm 2$ & & $19 \pm 2$ & & & & & & & \\
\hline Reduced & 62 & $44 \pm 8$ & & $37 \pm 7$ & & $19 \pm 5$ & & & & & & & \\
\hline Type of conditioning & & & .03 & & .03 & & .59 & & .007 & & .01 & & NS \\
\hline Chemotherapy-based & 450 & $55 \pm 3$ & & $25 \pm 2$ & & $19 \pm 2$ & & 1.0 & & 1.0 & & - & \\
\hline TBI-based & 171 & $63 \pm 4$ & & $18 \pm 3$ & & $19 \pm 3$ & & $\begin{array}{l}0.64 \\
(0.46- \\
0.88)\end{array}$ & & $\begin{array}{l}0.52 \\
(0.31- \\
0.86)\end{array}$ & & - & \\
\hline Source of stem cells & & & .015 & & .0008 & & .59 & & .01 & & .01 & & NS \\
\hline Bone marrow & 346 & $63 \pm 3$ & & $17 \pm 3$ & & $20 \pm 3$ & & 1.0 & & 1.0 & & - & \\
\hline Peripheral blood & 294 & $51 \pm 3$ & & $30 \pm 3$ & & $19 \pm 2$ & & $\begin{array}{l}1.33 \\
(1.01- \\
1.79)\end{array}$ & & $\begin{array}{l}1.63(1.11- \\
2.41)\end{array}$ & & - & \\
\hline Year of transplantation & & & .49 & & .21 & & .02 & & .045 & & NS & & .02 \\
\hline$<2003$ & 377 & $57 \pm 3$ & & $22 \pm 2$ & & $22 \pm 2$ & & 1.0 & & - & & 1.0 & \\
\hline$\geq 2003$ & 263 & $60 \pm 4$ & & $24 \pm 3$ & & $15 \pm 3$ & & $\begin{array}{l}0.71 \\
\quad(0.52-1)\end{array}$ & & - & & $\begin{array}{l}0.58 \\
(0.36- \\
0.93)\end{array}$ & \\
\hline
\end{tabular}

$K M$ Kaplan-Meier estimate, $C I$ cumulative incidence, $H R$ hazard ratio

Results are presented as percent \pm standard error 
Although the probabilities of LFS did not change markedly over time, in a multivariate model adjusted for other potential prognostic factors, the risk of failure for transplantations performed after 2002 was significantly reduced in comparison with the preceding period $(\mathrm{HR}=$ 0.71; Table 2). As shown in Table 3, patients treated with MRD-HSCT between 2003 and 2006 were characterized by higher age, shorter interval from diagnosis to transplantation as well as more frequent use of PBSCT and reduced intensity regimens, compared to years 1990-2002.

In the whole study group, independently from the year of transplantation, the probability of LFS was adversely affected by the recipient age $\geq 40$ years $(H R=1.33)$, the diagnosis of $\operatorname{ALL}(\mathrm{HR}=1.32)$ and the use of peripheral blood as a source of stem cells ( $\mathrm{HR}=1.33)$, while the use of $\mathrm{TBI}(\mathrm{HR}=0.64)$ and longer interval from diagnosis to transplantation $(\mathrm{HR}=0.69)$ were associated with better outcome (Table 2).

The univariate analysis revealed that the probability of LFS was significantly lower for patients treated with reduced-intensity regimens (RIC) compared to myeloablative conditioning (MAC; $44 \pm 8 \%$ vs. $59 \pm 2 \%, p=0.02$ ), which resulted from increased RI $(37 \pm 2 \%$ vs. $22 \pm 8 \%, p=$ 0.02). As all RIC transplantations were performed with the use of peripheral blood stem cells, the conditioning intensity and stem cell source could not be included together in the Cox model. However, in a subgroup analysis restricted to PBSCT, no significant difference could be demonstrated for RIC compared to MAC. Therefore, in contrast to stem cells source, the regimen intensity has not been considered for multivariate analyzes.
The effect of stem cell source was further analyzed in subgroups defined by the diagnosis as well as with restriction to MAC transplantations only. For AML patients receiving myeloablative conditioning the probability of LFS was higher after BMT compared to PBSCT $(66 \pm 3 \%$ vs. $54 \pm 5 \%, p=0.025)$, which was mainly a consequence of reduced RI ( $16 \pm 3 \%$ vs. $27 \pm 4 \%, p=0.01)$. In contrast, in a cohort of ALL, no significant influence on outcome could be demonstrated for the stem cell source. The comparison of patients receiving BMT and PBSCT revealed that the use of peripheral blood was associated with significantly increased recipient age [41 years (range, 16-69 years) vs. 31 (16-58), $p<0.0001]$, and shorter interval from diagnosis to MRD-HSCT [200 days (range, 75-933 days) vs 178 (range, 50-798),$p<0.0001]$. The association of source of stem cell was studied before 2003 and in years 2003-2006. Before 2003, LFS was $45 \pm 5 \%$ for patients receiving PBSCT compared to $63 \pm 3 \%$ for those receiving BMT $(p=0.002)$, while in the later period, LFS was $59 \pm 5 \%$ and $63 \pm 8 \%$, respectively $(p=0.52)$.

The effect of conditioning regimen on outcome was observed for both AML and ALL subgroups. In AML patients, the use of TBI-based conditioning resulted in decreased incidence of NRM as compared to chemotherapy alone $(11 \pm 4 \%$ vs. $20 \pm 2 \%, p=0.04)$, which translated into higher LFS $(70 \pm 6 \%$ vs. $57 \pm 3 \%, p=0.01)$. ALL patients treated with TBI experienced significantly less relapses as compared to chemotherapy-based regimens (18 $\pm 4 \%$ vs. $34 \pm 6 \%, p=0.009$ ), although the impact of conditioning on LFS was not significant.
Table 3 Comparison of MRDHSCT performed between 1990-2002 and 2003-2006

\begin{tabular}{llll}
\hline Year of transplantation & $1990-2002$ & $2003-2006$ & $P$ value \\
\hline$N$ & 377 & 263 & \\
Median patient age, range (years) & $33(16-69)$ & $38(16-61)$ & .0003 \\
Median interval from diagnosis to transplantation, range (days) & $192(62-933)$ & $188(50-601)$ & .007 \\
Diagnosis & & & .95 \\
AML & $270(72 \%)$ & $189(72 \%)$ & \\
ALL & $107(28 \%)$ & $74(28 \%)$ & $<.0001$ \\
Conditioning intensity & & & \\
Myeloablative & $354(94 \%)$ & $224(85 \%)$ & \\
Reduced & $23(6 \%)$ & $39(15 \%)$ & .85 \\
Type of conditioning & & & \\
Chemotherapy-based & $263(72 \%)$ & $187(71 \%)$ & \\
TBI-based & $101(28 \%)$ & $75(29 \%)$ & \\
Unknown & 12 & 1 & \\
Source of stem cells & & & \\
Bone marrow & $262(69 \%)$ & $84(32 \%)$ & \\
Peripheral blood & $115(31 \%)$ & $179(68 \%)$ & \\
\hline
\end{tabular}




\section{Discussion}

The outcome of patients treated with MRD-HSCT depends on a number of factors associated with the recipient, donor, and graft characteristics making direct comparisons between various study populations difficult. It may be hypothesized that in the early period transplant centers tend to select patients with favorable characteristics and low risk of NRM. With growing experience and increasing number of transplantations, this preselection should become less evident. In our study group including 640 MRD-HSCT performed in Eastern Europe for CR1 acute leukemia patients, between 1990 and 2006, 41\% of procedures were done within last 4 years of this period, which reflects growing transplant activity in the region. The procedure characteristics have been changing with increasing recipient age, shorter interval from diagnosis to HSCT, and more frequent use of RIC and PBSCT between 2003 and 2006. Despite these features, which in multivariate models were found to adversely affect outcome, the 2-year probability of LFS increased and reached the level of $60 \%$. The major improvement was observed in terms of the NRM, which in recent years decreased to $15 \%$. Reasons of this phenomenon may only be a subject of speculation, but probably better control of infections and GVHD should be considered. On the other hand, it may be speculated that in recent years, transplant centers preferred to use conditioning regimens with partially reduced intensity not fulfilling, however, the arbitrary criteria of RIC. Unfortunately, in this registry-based analysis, we were unable to evaluate this factor in the multivariate models due to insufficient data.

Our findings regarding NRM are of particular importance as high mortality rates have been raised a major counterargument to use MRD-HSCT in frontline therapy of adults with acute leukemia, especially in ALL. In a recently published study on a large population of patients, Goldstone at al. failed to demonstrate advantage of MRDHSCT over conventional-dose chemotherapy in a setting of high-risk ALL; however, the 2 years NRM rate for patients having an HLA-identical sibling was as high as $36 \%$ [3]. In the largest so far retrospective analysis including 2234 AML and ALL patients treated with MRD-HSCT in CR1 between 1994 and 2000, the NRM rate equaled 23\% [16]. With all the limitations regarding potential selection bias, the results obtained in Eastern Europe seem encouraging. As analyses similar to our one have not been published in recent years, it may only be speculated that our findings reflect a global trend for reduction of NRM in acute leukemia patients. From the reasons given before, confirmation of such a trend seems essential to facilitate treatment decisions in this group of patients.

The univariate and multivariate analysis of prognostic factors revealed several unexpected findings. In particular, the effects of stem cell source and type of conditioning appear intriguing. Comparison of bone marrow and peripheral blood MRD-HSCT was a subject of several randomized studies, all including heterogeneous populations with regard to both the diagnosis and the disease status at transplantation [17-22]. Recently updated results of the IBMTR/EBMT study revealed that for CR1 acute leukemia patients both sources of stem cells are equivalent with regard to all LFS, RI, and NRM [23]. In a metaanalysis performed for nine randomized trials, no difference was found for early stage leukemia, while patients with advanced AML benefited from the use of PBSCT [24]. On the other hand, in a retrospective study, based on the EBMT registry, Ringden at al. demonstrated higher RI for ALL CR1 patients receiving PBSCT compared to BMT, whereas no differences were found for AML [16]. In our study, the use PBSCT adversely affected LFS as a consequence of increased RI, which however, was observed only before 2003 and not in more recent period. Reliable interpretation of our results would require more detailed information on disease-related risk factors, particularly cytogenetic and molecular features that were unavailable in the current analysis.

TBI-based conditioning is widely accepted for ALL patients undergoing MRD-HSCT although until now, there is no direct evidence for its advantage over chemotherapy-based regimens [25]. In case of AML, the issue is even more controversial as some studies demonstrated better LFS after TBI compared to busulfan in combination with cyclophosphamide, while in other ones, such effect could not be confirmed [26-28]. A long-term follow-up of four randomized trials revealed a tendency for increased LFS and OS after TBI-based compared to busulfan-based conditioning [29]. In our analysis, the use of TBI was associated with improved LFS. In a cohort of ALL, TBI-based conditioning resulted in decreased risk of relapse, while in AML, with reduced NRM. These findings seem to support the use of TBI in acute leukemia patients, which, however, should be interpreted with caution taking into account the retrospective nature of our study.

We conclude that results of MRD-HSCT for acute leukemia in Eastern Europe improved over time, as a consequence of decreased NRM, despite increasing recipient age. Our results should enhance extended use of this procedure to be offered to a larger number of acute leukemia patients. This is of particular importance in countries were the transplant program is still in the early phase of development, as a consequence of insufficient financial support or unfavorable regulations. Further analyses are required to determine association of MRD-HSCT outcome with country- and center-specific socioeconomical factors. 
Acknowledgements The following investigators are acknowledged for their contribution to this study: Francesco Frassoni, Genova, Italy; Dragana Stamatovic, Belgrade, Serbia; Ladislav Jebavy, Hradec Kralove, Czech Republic; Bozena Marianska, Warsaw, Poland; Hele Everaus, Tartu, Estonia; Kazimierz Kuliczkowski, Wroclaw, Poland; Andrea Moicean, Bucharest, Romania; Aleksander B. Skotnicki, Cracow, Poland; Alicja Chybicka, Wroclaw, Poland; Jacek Wachowiak, Poznan, Poland; Jerzy Kowalczyk, Anna Dmoszynska, Lublin, Poland; Jolanta Gozdzik, Cracow, Poland; Petr Sedlacek, Prague, Czech Republic; Dusan Pejin, Novi Sad, Serbia; Jelena Rascon, Vilnius, Lithuania; and Miroslaw Markiewicz, Katowice, Poland.

\section{References}

1. Thomas X, Boiron JM, Huguet F et al (2004) Outcome of treatment in adults with acute lymphoblastic leukemia: analysis of the LALA-94 trial. J Clin Oncol 22:4075-4086. doi:10.1200/ JCO.2004.10.050

2. Labar B, Suciu S, Zittoun R et al (2004) Allogeneic stem cell transplantation in acute lymphoblastic leukemia and nonHodgkin's lymphoma for patients \&lt;or $=50$ years old in first complete remission: results of the EORTC ALL-3 trial. Haematologica 89:809-817

3. Goldstone AH, Richards SM, Lazarus HM et al (2007) In adults with standard-risk acute lymphoblastic leukemia (ALL) the greatest benefit is achieved from a matched sibling allogeneic transplant in first complete remission (CR) and an autologous transplant is less effective than conventional consolidation/ maintenance chemotherapy in All patients: final results of the international ALL trial (MRC UKALL XII/ ECOG E2993). Blood 111:1827-1833. doi:10.1182/blood-2007-10-116582

4. Zittoun RA, Mandelli F, Willemze R et al (1995) Autologous or allogeneic bone marrow transplantation compared with intensive chemotherapy in acute myelogenous leukemia. European Organization for Research and Treatment of Cancer (EORTC) and the Gruppo Italiano Malattie Ematologiche Maligne dell'Adulto (GIMEMA) Leukemia Cooperative Groups. N Engl J Med 332:217-223. doi:10.1056/NEJM199501263320403

5. Gale RP, Büchner T, Zhang MJ et al (1996) HLA-identical sibling bone marrow transplants vs chemotherapy for acute myelogenous leukemia in first remission. Leukemia 10:1687-1691

6. Cassileth PA, Harrington DP, Appelbaum FR et al (1998) Chemotherapy compared with autologous or allogeneic bone marrow transplantation in the management of acute myeloid leukemia in first remission. N Engl J Med 339:1649-1656. doi:10.1056/NEJM199812033392301

7. Reiffers J, Stoppa AM, Attal M et al (1996) Allogeneic vs autologous stem cell transplantation vs chemotherapy in patients with acute myeloid leukemia in first remission: the BGMT 87 study. Leukemia 10:1874-1882

8. Burnett AK, Wheatley K, Goldstone AH et al (2002) The value of allogeneic bone marrow transplant in patients with acute myeloid leukaemia at differing risk of relapse: results of the UK MRC AML 10 trial. Br J Haematol 118:385-400. doi:10.1046/j.13652141.2002.03724. $\mathrm{x}$

9. Cornelissen JJ, van Putten WL, Verdonck LF et al (2007) Results of a HOVON/SAKK donor versus no-donor analysis of myeloablative HLA-identical sibling stem cell transplantation in first remission acute myeloid leukemia in young and middle-aged adults: benefits for whom? Blood 109:3658-3666. doi:10.1182/ blood-2006-06-025627

10. Gratwohl A, Baldomero H, Frauendorfer K et al (2008) The EBMT activity survey 2006 on hematopoietic stem cell transplan- tation: focus on the use of cord blood products. Bone Marrow Transplant 41:687-705. doi:10.1038/sj.bmt.1705956

11. Gratwohl A, Baldomero H, Schwendener A et al (2007) Predictability of hematopoietic stem cell transplantation rates. Haematologica 92:1679-1686. doi:10.3324/haematol.11260

12. Gratwohl A, Baldomero H, Labar B et al (2004) Evolution of hematopoietic stem cell transplantation in Eastern and Western Europe from 1990 to 2003. A report from the EBMT activity survey. Croat Med J 45:689-694

13. Frassoni F, Labopin M, Powles R et al (2000) Effect of centre on outcome of bone-marrow transplantation for acute myeloid leukaemia. Acute Leukaemia Working Party of the European Group for Blood and Marrow Transplantation. Lancet 355:13931398. doi:10.1016/S0140-6736(00)02137-1

14. Gooley TA, Leisenring W, Crowley J, Storer BE (1999) Estimation of failure probabilities in the presence of competing risks: new representations of old estimators. Stat Med 18:695706. doi:10.1002/(SICI) 1097-0258(19990330)18:6<695::AIDSIM60 $>3.0 . \mathrm{CO} ; 2-\mathrm{O}$

15. Fine JP, Gray RJ (1999) A proportional hazards model for subdistribution of a competing risk. J Am Stat Assoc 94:496509. doi: $10.2307 / 2670170$

16. Ringdén O, Labopin M, Bacigalupo A et al (2002) Transplantation of peripheral blood stem cells as compared with bone marrow from HLA-identical siblings in adult patients with acute myeloid leukemia and acute lymphoblastic leukemia. J Clin Oncol 20:4655-4664. doi:10.1200/JCO.2002.12.049

17. Champlin RE, Schmitz N, Horowitz MM et al (2000) Blood stem cells compared with bone marrow as a source of hematopoietic cells for allogeneic transplantation. IBMTR Histocompatibility and Stem Cell Sources Working Committee and the European Group for Blood and Marrow Transplantation (EBMT). Blood 95:3702-3709

18. Powles R, Mehta J, Kulkarni S et al (2000) Allogeneic blood and bone marrow stem-cell transplantation in haematological malignant diseases: a randomized trial. Lancet 355:1231-1237. doi:10.1016/S0140-6736(00)02090-0

19. Blaise D, Kuentz M, Fortanier C et al (2000) Randomized trial of bone marrow versus lenograstimprimed blood cell allogeneic transplantation in patients with early-stage leukemia: a report from the Societe Franciase de Greffe de Molle. J Clin Oncol 18:537546

20. Bensinger WI, Martin PJ, Storer B et al (2001) Transplantation of bone marrow as compared with peripheral-blood cells from HLAidentical relatives in patients with hematologic cancers. $\mathrm{N}$ Engl $\mathrm{J}$ Med 344:175-181. doi:10.1056/NEJM200101183440303

21. Schmitz N, Beksac M, Hasenclever D et al (2002) Transplantation of mobilized peripheral blood cells to HLA-identical siblings with standard risk leukemia. Blood 100:761-767. doi:10.1182/blood2001-12-0304

22. Couban S, Simpson DR, Barnett MJ et al (2002) A randomized multi-center comparison of bone marrow and peripheral blood in recipients of matched sibling allogeneic transplants for myeloid malignancies. Blood 100:1525-1531. doi:10.1182/blood-2002-010048

23. Schmitz N, Eapen M, Horowitz MM et al (2006) Long-term outcome of patients given transplants of mobilized blood or bone marrow: A report from the International Bone Marrow Transplant Registry and the European Group for Blood and Marrow Transplantation. Blood 108:4288-4290. doi:10.1182/blood-200605-024042

24. Stem Cell Trialists' Collaborative Group (2005) Allogeneic peripheral blood stem-cell compared with bone marrow transplantation in the management of hematologic malignancies: an individual patient data meta-analysis of nine randomized trials. J Clin Oncol 23:5074-5087. doi:10.1200/JCO.2005.09.020 
25. Hahn T, Wall D, Camitta B et al (2006) The role of cytotoxic therapy with hematopoietic stem cell transplantation in the therapy of acute lymphoblastic leukemia in adults: an evidence-based review. Biol Blood Marrow Transplant 12:1-30. doi:10.1016/j. bbmt.2005.10.018

26. Hahn T, Wall D, Camitta B et al (1992) Allogeneic bone marrow transplantation for acute myeloid leukemia in first remission: a randomized trial of a busulfan-cytoxan versus cytoxan-total body irradiation as preparative regimen: a report from the Groupe d'Etudes de la Greffe de Moelle Osseuse. Blood 79:2578-2582

27. Ringden O, Ruutu T, Remberger M et al (1994) A randomized trial comparing busulfan with total body irradiation as conditioning in allogeneic marrow transplant recipients with leukemiaa report from the Nordic Bone Marrow Transplantation Group. Blood 83:2723-2730

28. Litzow MR, Pérez WS, Klein JP (2002) Comparison of outcome following allogeneic bone marrow transplantation with cyclophosphamide-total body irradiation versus busulphancyclophosphamide conditioning regimens for acute myelogenous leukaemia in first remission. $\mathrm{Br} \mathrm{J}$ Haematol 119:1115-1124. doi:10.1046/j.1365-2141.2002.03973.x

29. Socié G, Clift RA, Blaise D et al (2001) Busulfan plus cyclophosphamide compared with total-body irradiation plus cyclophosphamide before marrow transplantation for myeloid leukemia: long-term follow-up of 4 randomized studies. Blood 98:3569-3574. doi:10.1182/blood.V98.13.3569 